\title{
Research on Optimization of Earned Value Management Method in Engineering Budget Management
}

\author{
$\mathrm{Ji} \mathrm{Gedi}^{*}{ }^{* 1,2} \mathrm{Wu}$ Yunna ${ }^{1}$ and Chang Qing ${ }^{2}$ \\ ${ }^{I}$ School of Business and Administration, North China Electric Power University, Beijing, 102206, P.R. China \\ ${ }^{2}$ School of Management, Inner Mongolia University of Technology, Huhhot, 010051, P.R. China
}

\begin{abstract}
Earned Value Management Method (EVM), widely used in the world, is a project management method of costschedule integrated control. But the traditional EVM sometimes cannot provide an accurate result. In this paper, a practical method is given to analyze the project performance, in which the Network Diagram Method and the Critical Path Method have been introduced into EVM system that can better reflect the practical situation of a project. This improved method can be referred to assub-level earned value analysis method. This method can correct variance in the duration and cost forecast of the traditional EVM, and can also provide more information about the cause analysis.
\end{abstract}

Keywords: Sub-level Earned Value, performance evaluation, Earned Value Management, Critical Path Method (CPM).

\section{INTRODUCTION}

Earned value management method(EVM) accepted throughout the world of project management is a method of cost-schedule control, and this method has already been put forward by the industrial engineer of the American factory in the $20^{\text {th }}$ century. It was formally introduced in the costcontrol system in 1962, recorded in the "System Rules" made by American Defense Department in 1967 [1], and widely used in the programs of the American Energy Department, Traffic Department and so on, and also obtained good results in the aspect of investment and progress control management.

At present, Earned Value Management (EVM) has already been the main method of project management in the performance evaluation of schedule-cost implementation. The main content of this method is as follows:

The three index systems of earned value management:

- Planned value (pv) is the budgeted cost for the work scheduled to be done. This is also known as BCWS (Budgeted Cost of Work Scheduled), and PV is calculated by multiplying the budgetary price of one activity by the workload of the same activity.

$P V=\sum_{0}^{t} P W \times B C(0 \leq \mathrm{t} \leq \mathrm{T})$

PW: planned workload; BC: budget unit cost; t: present checking time; $\mathrm{T}$ : project finish time

- Actual Costs (AC) is simply the money spent for the work accomplished. This is also known as the actual cost of work performed (ACWP).

*Address correspondence to this author at the School of Business and Administration North China Electric Power University, Huhhot, 102206 , P.R. China; Tel: +8618947102205.E-mail: jgd1311@126.com
$\mathrm{AC}(\mathrm{t})=\sum_{0}^{\mathrm{t}} \mathrm{RW} \times \mathrm{RC}(0 \leq \mathrm{t} \leq \mathrm{T})$

RW: real workload; RC: real unit cost; t: present checking time; $\mathrm{T}$ : project finish time

- Earned value (EV) is the percentage of the total budget actually completed at a point in time. This is also known as the Budgeted Cost of Work Performed (BCWP). EV is calculated by multiplying the budget for an activity by the real workload for that activity.

$E V(\mathrm{t})=\sum_{0}^{t} R W \times B C \quad(0 \leq \mathrm{t} \leq \mathrm{T})$

RW: real workload; $\mathrm{BC}$ : budget unit cost; $\mathrm{t}$ : present checking time; $\mathrm{T}$ : project finish time

Four evaluation indexes are needed for the earned value management:

\subsection{Two Variance Evaluation Indexes}

$\mathrm{CV}$ (Cost Variance) and the calculation formula is:

$C V=E V-A C$

If $\mathrm{CV}<0$, it indicates that the result of cost performance is not good, which means the real cost has already exceeded the budget.

If $\mathrm{CV}>0$, it indicates that the real cost is within the budget.

If $\mathrm{CV}=0$, it indicates that the real cost is equal to the budget.

If the cost variance is negative, it means that the project cost is overspending, or the project cost is surplus.

SV (Schedule Variance) 
It is similar to the $\mathrm{CV}$; if $\mathrm{SV}$ is negative, it indicates that the project schedule falls behind, or it means the project process is ahead. The calculation formula is:

$\mathrm{SV}=\mathrm{EV}-\mathrm{PV}$

If $\mathrm{SV}<0$, it indicates that the real schedule is less than the planned quantity, which means the schedule is delayed.

If $\mathrm{SV}>0$, it indicates that the real schedule is more than the planned quantity, which means the schedule is ahead.

If $\mathrm{SV}=0$, it indicates that the real schedule coincides with the plan.

\subsection{Two Index Numbers of the Evaluation Index}

SPI (Schedule Performance Index), the calculation formula is:

$S P I=\frac{E V}{P V}$

If $\mathrm{SPI}=1$, it indicates that the project proceeds according to the plan;

If $\mathrm{SPI}>1$, it indicates that the project schedule is ahead;

If $\mathrm{SPI}<1$, it indicates that the project schedule is delayed.

CPI (Cost Performance Index), its calculation formula is:

$C P I=\frac{A C}{E V}$

If $\mathrm{CPI}=1$, it indicates that the real cost fits the budget.

If $\mathrm{CPI}>1$, it indicates that the real cost is less than the budget.

If $\mathrm{CPI}<1$, it indicates that the real cost is more than the budget.

\subsection{Two Predictor Variables in the Method of Earned Value Management}

EAC (Estimated Cost at Completion), the EAC has three methods.

a) Assuming that the unfinished task iscompleted in the present efficiency.

$E C A=\frac{B A C}{C P I}$

And BAC is the budget at completion.

b) Assuming that the unfinished task iscompleted in the planned efficiency.

The forecasted cost at completion is equal to the actual cost of work performed plus the total budget cost, and subtracting $\mathrm{EV}$, the calculation formula is:

$$
E A C=A C W P+(B A C-E V)
$$

Or

$$
E A C=A C W P+(B A C-B C W P)
$$

c) Reappraising the cost of the residual workload to forecast the total cost. This method is necessary, if the project plan greatly deviates from the actual or the project condition already experienced material changes. The calculation formula of this method is:

$F C A C-A C W P-R C R W$

The forecasted cost at completion is equal to the actual cost of the work performed plus the reappraised cost of the residual workload (RCRW).

\subsection{Estimated Completion Date (ECD)}

The ECD (Estimated Completion Date) forecast is the most difficult, and also has the most arguments. The common forecast methods are the following two methods:

- Assuming that the residual work is done according to the original plan work efficiency, the plan's completion time of the residual work is calculated to obtain the final ECD.

- Assuming that the residual work is done according to the present work efficiency, the ECD's calculation formula is: $\mathrm{ECD}=\mathrm{OPD} / \mathrm{SPI}$ (OPD: Original Project Duration)

If there are unplanned events (bad weather, capital source interrupted and so on) the construction work during the project performance stops. In addition, using only historic data to forecast the completion date will probably result in major errors with a wrong completion date. Because of this, the first method is usually taken when the ECD and cost/progress execution state diagram is drawn. The information regarding project schedule and cost execution state is obtained by comprehensive analysis of the above indexes to achieve the evaluation of the project construction performance and provide guidance and advice for the followup work.

Fig. (1) shows a project performance report chart,which presents the relationship between the $\mathrm{PV}, \mathrm{AC}$ and $\mathrm{EV}$, and forecasts trends of the project completion cost and time based on the project present schedule situation.

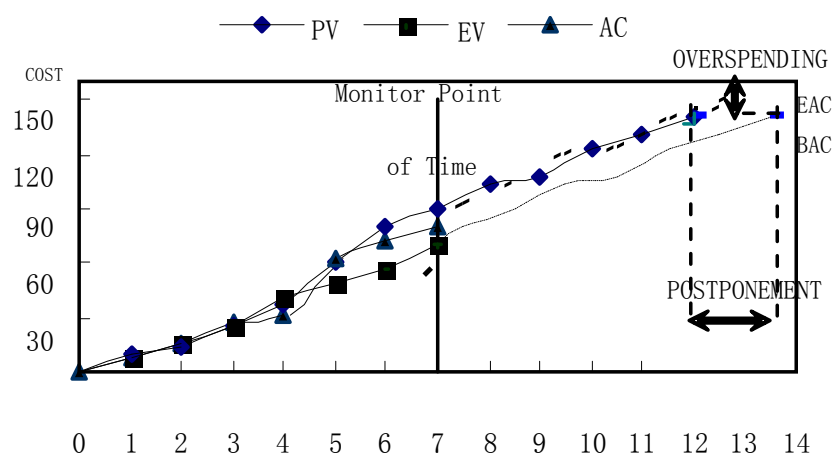

Fig. (1). Cost - Schedule trend.

\section{THE SHORTCOMING OF THE EVM DURING THE APPLICATION}

The earned value method (EVM) is recognized as a viable method for evaluating and forecasting project cost performance. However, its application to schedule performance forecasting has been limited due to poor accuracy in predicting project durations [2]. Leila Moslemi Naeni [3] presents a new fuzzy-based earned value model 
with the advantage of developing and analyzing the earned value indices, and the time and the cost estimates at completion under uncertainty.

Rodney [4] studied the traditional EVM and analyzed the problems by treating the project as a whole. This method did not consider the activities of the project WBS or the structure of Work Package, and all the analysis and operations were based on the summary of the project cost (as the actual operation). If there are some delayed projects, this makes the EV less efficient than the planned cost in next level (or all following levels) of the WBS. But if some actual projects are ahead, this makes the EV more efficient than the planned cost, and finally the cumulative EV of the whole project is enough, which can also obtain good apparent project performance, but it does not really reflect the actual schedule execution of the project. If only three indexes of the whole project are analyzed, the result probably has significant variance with the actual execution situation, concluding that it is not consistent with the actual situation,thusleading the EVM towards failure in the control of cost-schedule.

Besides, the traditional EVM pays attention to analyzing the project performance in the macroscopic aspect, but is not clear about the nature of the projects' internal accomplished work and the execution situation of the critical path activities. Fleming \& Keppelman [5] analyzed that when setting up the earned value datum line, the critical path network needs to be embedded, the time schedule needs to be established, and resources need to be allocated. But CPM (Critical Path Method) is applied in the project schedule management just treated as one kind of tool that is parallel to the Earned Value. If the project manager pays attention to the Earned Value and CPM at the same time when they evaluate the present schedule execution situation, and the information of the two analysis methods provided is different or the conclusions are inconsistent, the project management has to make judgments between the analysis results, which undoubtedly increases the difficulty of decision and workload.
In conclusion, the shortcoming of the traditional EVM discussed in this paper can be summarized as: it pays attention to the analysis of the whole, while ignoring the logical relationship of the internal work in the management of engineering. Moreover, it only stresses the total forecast while ignoring the execution situation of the project's internal work.

\section{SUB-LEVEL EARNED VALUE METHOD}

In order to avoid most of the variance and disadvantages of the traditional Earned Value Analysis, the Sub-level EVM is proposed which treats the traditional Earned Value Analysis method as a theoretical base, and combines the schedule network diagram and critical path method to make Earned Value Analysis. In sub-level EVM, the cost-schedule execution situation of Sub-level projects is comprehensively considered. The differences in the analysis content and steps between the traditional EVM and the new method are shown in Table $\mathbf{1}$.

\section{COMPARISON BETWEEN TRADITIONAL EVM AND SUB-LEVEL EVM}

The following three tables show the statistics of the schedule execution situation of one construction project.

\subsection{The Application of Traditional EVM}

This project consists of five sub-level projects. Using Tables 2-4 to record detailed statistics of the sub-level project schedule and the actual construction date, which are added to gain the three indexes data needed in the project performance evaluation. Based on the detailed data of the above tables, the present evaluation situation of the seventh month of the project is as follows:

$$
\begin{aligned}
& \mathrm{CPI}=\mathrm{EV} / \mathrm{AC}=85 / 81=1.049>1 \\
& \mathrm{SPI}=\mathrm{EV} / \mathrm{PV}=88 / 90=0.944<1 \\
& \mathrm{CV}=\mathrm{EV}-\mathrm{AC}=85-81=0.4 \text { million }
\end{aligned}
$$

\begin{tabular}{|c|c|c|}
\hline Step & Traditional EVM & Sub-level EVM \\
\hline 1 & \multicolumn{2}{|l|}{ Establish WBS } \\
\hline 2 & \multicolumn{2}{|l|}{ Make project schedule plan, and schedule work time of each work package } \\
\hline 3 & \multicolumn{2}{|c|}{ Distribute budget to each level project in WBS, especially for each monitored point of time } \\
\hline 4 & $\begin{array}{l}\text { Summarize PV、EV、AC date, establish the three-index systems of } \\
\text { total project }\end{array}$ & $\begin{array}{l}\text { Establish the three-index systems of sub-level projects, draw construction } \\
\text { schedule network diagram and find out the critical path, then indicate the } \\
\text { relevance and time relaxation situation among the sub-level projects. }\end{array}$ \\
\hline 5 & $\begin{array}{l}\text { Correct and forecast the accomplished cost based on the total project } \\
\text { dates. }\end{array}$ & $\begin{array}{l}\text { Analyze and forecast each sub-level work applied EVM, correct EAC of } \\
\text { each sub-level work and add them up as the EAC of project. }\end{array}$ \\
\hline 6 & $\mathrm{ETC}=\mathrm{OPD} / \mathrm{SPI}$ or Other Methods & $\begin{array}{l}\text { Evaluate the variance between actual schedule and planned schedule, } \\
\text { combined with critical path network diagram. }\end{array}$ \\
\hline 7 & $\begin{array}{l}\text { Draw the cost-schedule trend chart based on the analysis of three- } \\
\text { index system. }\end{array}$ & $\begin{array}{l}\text { Analyze three-index system of each sub-level work, and draw cost- } \\
\text { schedule trend chart combined with critical path network diagram. }\end{array}$ \\
\hline
\end{tabular}

Table 1. The comparison in method and step between traditional EVM and sub-level EVM. 
$\mathrm{SV}=\mathrm{EV}-\mathrm{PV}=85-90=-0.5$ million

$\mathrm{EAC}=\mathrm{BAC} / \mathrm{CPI}=140 / 1.1=13.3461$ million

The evaluation result is clearly reflected in Fig. (2); the $\mathrm{CV}$ is large $(\mathrm{CV}=\mathrm{EV}-\mathrm{AC}=85-81=0.4$ million $)$, and the actual schedule is delayed a bit compared with the planned schedule $(\mathrm{SPI}<1)$. The project works out well from the evaluation of project performance by the traditional EVM. But a lot of problems can be found if Sub-level EVM is considered.

\subsection{The Application of Sub-level EVM}

\subsubsection{Cost Analysis}

Fig. (5) deals with the total cost based on the project progress situation of the five sub-level projects. Among them, the cost to complete forecast of project $\mathrm{A}$ and $\mathrm{C}$ is corrected and estimated based on the EVM (The estimation methods of EAC are different because of different execution situation. Now one method is selected, and the others can be found in the literature [6]. Project B and E have already been completed, Therefore, the EAC can be obtained from the actual direct cost. Work performance of project $\mathrm{D}$ cannot be

Table 2. Budget table of project datum line.

\begin{tabular}{|c|c|c|c|c|c|c|c|c|c|c|c|c|c|c|c|}
\hline \multicolumn{4}{|c|}{ Project Information } & \multicolumn{12}{|c|}{ PV（Ten Thousand Yuan） } \\
\hline $\begin{array}{l}\text { Work } \\
\text { No. }\end{array}$ & $\begin{array}{c}\text { Planned } \\
\text { Schedule Month }\end{array}$ & $\begin{array}{l}\text { Preceding } \\
\text { Activity }\end{array}$ & Slack & \multicolumn{12}{|c|}{ Monitor Point of Time（Month） } \\
\hline A & 8 & - & 1 & & & & 4 & 11 & 19 & 22 & 25 & 26 & 33 & 34 & \\
\hline $\mathrm{B}$ & 3 & - & 0 & 9 & 13 & 21 & & & & & & & & & \\
\hline $\mathrm{D}$ & 4 & $\mathrm{C}$ & 0 & & & & & & & & & 2 & 9 & 16 & 26 \\
\hline $\mathrm{E}$ & 7 & - & 3 & & & 5 & 8 & 16 & 23 & 27 & 31 & 32 & & & \\
\hline \multicolumn{2}{|r|}{ Project } & \multicolumn{2}{|c|}{ accumulative PV } & 9 & 13 & 26 & 37 & 60 & 80 & 90 & 104 & 108 & 122 & 130 & 140 \\
\hline
\end{tabular}

Table 3. The newest workload budget statistic table.

\begin{tabular}{|c|c|c|c|c|c|c|c|c|c|c|c|c|c|c|}
\hline \multicolumn{4}{|c|}{ Project Information } & \multicolumn{11}{|c|}{ EV (Ten Thousand Yuan) } \\
\hline \multirow{2}{*}{$\begin{array}{l}\text { Work } \\
\text { No. }\end{array}$} & \multirow{2}{*}{$\begin{array}{c}\text { Project } \\
\text { Performance }\end{array}$} & \multirow{2}{*}{$\begin{array}{c}\text { Work } \\
\text { Development }\end{array}$} & \multirow{2}{*}{$\begin{array}{l}\text { Finished Work } \\
\text { Duration }\end{array}$} & \multicolumn{11}{|c|}{ Monitor Point of Time（Month） } \\
\hline & & & & 1 & 2 & 3 & 4 & 5 & 6 & 7 & 8 & 9 & 10 & 111 \\
\hline A & In progress & Delay & - & & & & & 3 & 10 & 14 & & & & \\
\hline B & Finished & Normal & 4 & 8.2 & 12 & 17 & 21 & & & & & & & \\
\hline $\mathrm{C}$ & In progress & Delay & - & & & & & 2 & 10 & 19 & & & & \\
\hline $\mathrm{D}$ & Not in work & - & - & & & & & & & & & & & \\
\hline $\mathrm{E}$ & Finished & Ahead & 6 & & 3 & 8 & 20 & 22 & 31 & 34 & & & & \\
\hline \multicolumn{2}{|c|}{ Project } & \multicolumn{2}{|c|}{ accumulative EV } & 8.2 & 15 & 25 & 41 & 48 & 72 & 85 & & & & \\
\hline
\end{tabular}

Table 4. The newest AC statistic table.

\begin{tabular}{|c|c|c|c|c|c|c|c|c|c|c|c|c|c|c|c|}
\hline \multicolumn{4}{|c|}{ Project Information } & \multicolumn{12}{|c|}{ AC (Ten Thousand Yuan) } \\
\hline \multirow{2}{*}{$\begin{array}{l}\text { Work } \\
\text { No. }\end{array}$} & \multirow{2}{*}{$\begin{array}{c}\text { Project } \\
\text { Performance }\end{array}$} & \multirow{2}{*}{$\begin{array}{c}\text { Work } \\
\text { Development }\end{array}$} & \multirow{2}{*}{$\begin{array}{c}\text { Finished Work } \\
\text { Duration }\end{array}$} & \multicolumn{12}{|c|}{ Monitor Point of Time（Month） } \\
\hline & & & & 1 & 2 & 3 & 4 & 5 & 6 & 7 & 8 & 9 & 10 & 11 & 12 \\
\hline A & In progress & Delay & - & & & & & 10 & 14 & & 15 & & & & \\
\hline $\mathrm{B}$ & Finished & Normal & 4 & 7 & 10 & 17 & 21 & & & & & & & & \\
\hline $\mathrm{C}$ & In progress & Delay & - & & & & & 11 & 15 & & 18 & & & & \\
\hline $\mathrm{D}$ & Not in work & - & - & & & & & & & & & & & & \\
\hline $\mathrm{E}$ & Finished & Ahead & 6 & & 6 & 8.5 & 11 & 20 & 23 & & 26 & & & & \\
\hline \multicolumn{2}{|r|}{ Project } & \multicolumn{2}{|c|}{ accumulative $\mathrm{AC}$} & 7 & 16 & 26.5 & 32 & 62 & 73 & & 81 & & & & \\
\hline
\end{tabular}


Table 5. Cost estimate at completion of sub-level project.

\begin{tabular}{|c|c|c|c|c|c|c|}
\hline & A & B & C & D & E & Accumulation(ten thousand) \\
\hline \hline BAC & 34 & 21 & 27 & 26 & 32 & $\sum \mathrm{BAC}=140$ \\
\hline $\mathrm{CPI}=\mathrm{EV} / \mathrm{AC}$ & 0.933 & & 0.9444 & & & \\
\hline $\mathrm{EAC}=\mathrm{BAC} / \mathrm{CPI}$ & 36.43 & 21 & 28.588 & 26 & 26 & $\sum \mathrm{EAC}=138.02$ \\
\hline
\end{tabular}

evaluated as it has not been started, therefore, the EAC is equal to the planned cost. Following this, the total of EAC can be calculated by adding the completed cost of the sublevel projects .According to the calculation of the above table, the sub-level project $\mathrm{A}$ and $\mathrm{C}$ required extra cost (shown in Fig. 3), though the cost of the total project did not exceed the total.

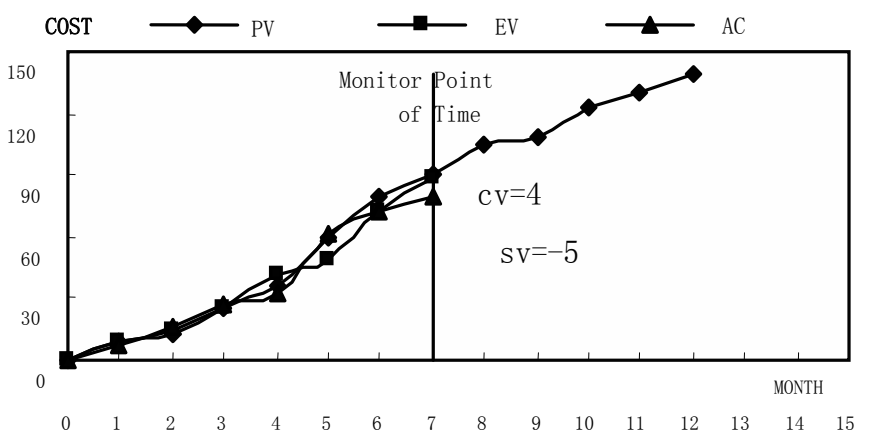

Fig. (2). Cost-schedule trend.

The total project cost is saved mainly because the project E saves so much during execution. When analyzing the total project from the angle of traditional EVM, it can only determine the execution situation of the total project cost, but cannot provide the necessary analysis to find the problems of the next level projects.

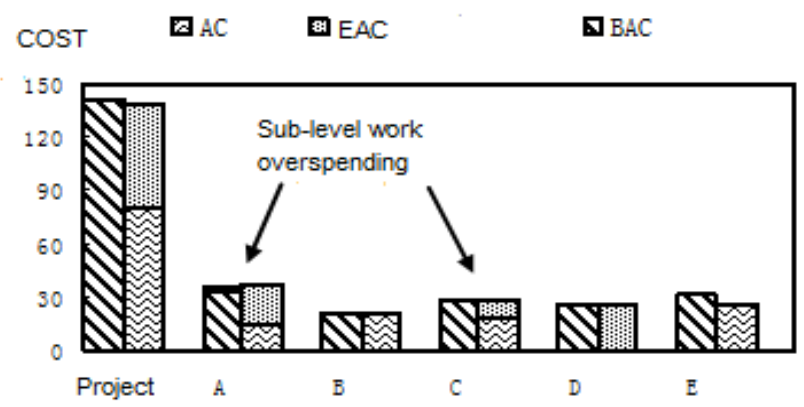

Fig. (3). Performance-forecast state of sub-level project cost.

\subsubsection{Schedule Forecast}

Fig. (5) shows the performance -forecast state chart of sub-level project cost. Projects A through E are shown, where the $\mathrm{CP}$ is $\mathrm{B} \rightarrow \mathrm{C} \rightarrow \mathrm{D}$, while $\mathrm{A}$ and $\mathrm{E}$ work independently, and construction times for both have different degrees of relaxation. Combined with the newest data of the Tables 2-4, the on-stream time of project A was delayed one month longer than the planned time, the actual cost exceeded a little(CV=EV-AC=14-15=-0.1million), because the present earned valve should have been completed in the first half of the sixth month of the project. It can be made sure that the project $A$ had already been delayed almost 2 months.Though project B started on time, its time of completion delayed 1 month and project $\mathrm{C}$, following project $\mathrm{B}$, which was postponed. As a result, the schedule of $\mathrm{CP}$ was delayed resulting in making the total project tardy. Project E was started earlier than planned, and completed the work 2 months earlier, therefore, it saved a lot of money ( $\mathrm{CV}=\mathrm{EV}-\mathrm{AC}=34-26=0.8$ million), as a result it earned considerable value for the total project. Rodney used proportional method in his paper and the calculation formula is: $\mathrm{ETC}=\mathrm{OPD} / \mathrm{SPI}$ (OPD: Original project duration), but the time and cost did not have the proportionate relationships in most of the project [7]. It would have major errors and even lead to erroneous results when forecasting the time of completion based only on the historical data. In this paper, such a hypothesis can be considered when estimating the time of completion, while the rest of the work remains according to plan. According to above discussion, the estimated time of completion are shown in Fig. (5). Compared with the traditional EVM, EAC and ECD are optimized in Sub-level EVM (shown in Table 5. and Fig. 5). Finally, the Cost-Schedule Trend is in Fig. (4).

\subsubsection{Comprehensive Analysis}

As shown in Fig. (4), the evaluation of the monitor point for the project is that the project cost is saved during the execution, and the forecast time of completion will be delayed 1 month. The reasons can be obtained easily from the analysis of Fig. (3) and Fig. (5). According to the comparison, it is obvious that the result of the analysis of traditional EVM showed large variance with the actual execution situation, but the Sub-level EVM given in this paper avoided most of this variance. Furthermore, using the same data, Sub-level EVM can provide more information about performance evaluation and reason analysis than the traditional EVM. Besides, the performance of cost and schedule on the noncritical path should be noted, because over-expenditure and schedule delay on the noncritical path may also lead to cost-schedule control failure.

\section{APPLICATION}

P8 software of PWC (Price Water House Coopers) company is widely applied in many large projects, and it is integrated with EVM to make multilayer plan management modes popular in many large projects. It can provide stable, timely, and exact data support, while at the same time, it also provides conditions for sub-level EVM application in each level of the project. At present, the software module exploitation of infrastructure projects performance evaluations, which uses the EVM and Sub-levels EVM as 

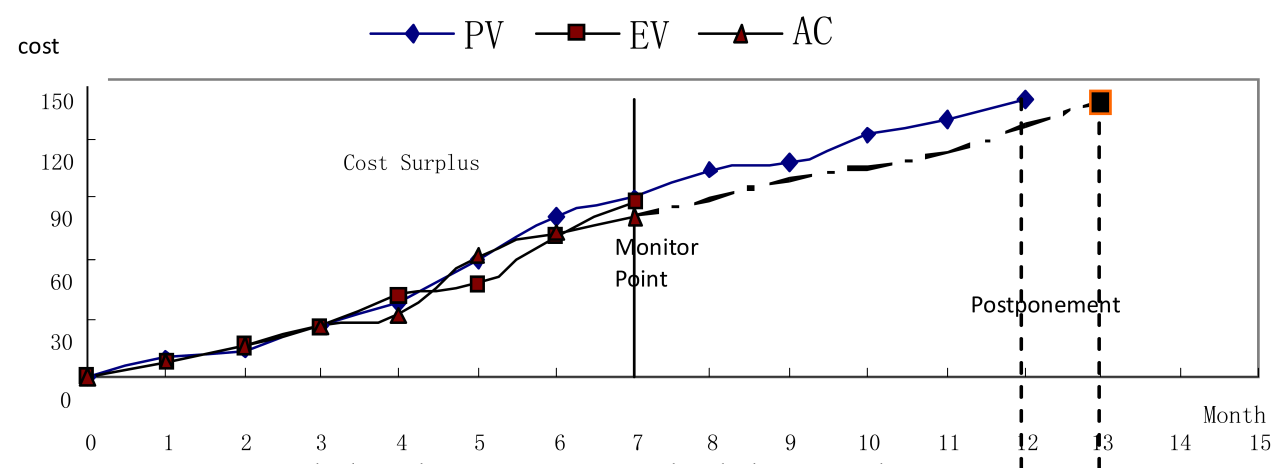

Fig. (4). Sub-level EVM cost-schedule trend.

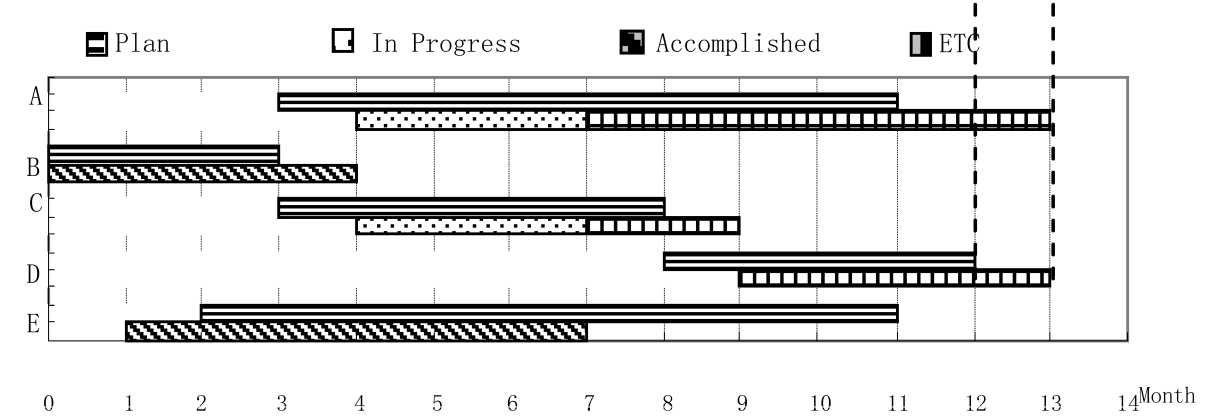

Fig. (5). Critical path schedule forecast.

the theoretical basis and is based on the Internet/Web structure [8], that has been primarily completed. It has already been embedded in PMIS (Project Management Information System), and has begun to be used in part of the construction management of electric power plant. Comparing and analyzing the advantages and disadvantages of the two methods in actual analysis and forecast gives important guidance.

\section{CONCLUSION}

The project example is aimed at illustrating that the traditional EVM has variance during the application of the cost/schedule integration control. The corrected sub-level EVM is more effective in the application of the same project. It is can be seen in the analysis that the sub-level EVM put forward in this article improved a lot in the aspect of performance evaluation and corrected forecast, and provided more reasons of analysis for the project than the traditional EVM. Therefore, it does not only allow the project leaders to know about the situation of the total project, but can also attain the reasons why it led to these results according to the project analysis of the next level.

In theory, EVM can be one universal method of execution performance evaluation method that can be used in all kinds of project management activities. But the first difficulty in the application of EVM is that the requirement of data is extremely high which needs high capital and a lot of human labor. To timely deal with large data in an effective manner, relying on fewer people is impossible. Christensen, David [9] analyzed the EVM for the costincome in the high cost of collecting data. The application cost of purchase and maintenance costs is far beyond the affordability for general projects. Because of this, the EVM is usually used in the large projects invested by the government such as national defense, energy sources and so on in most of the countries. It is believed that the EVM plays an important role in project management in future with wide application of PMIS. Though the sub-level EVM has corrected many deficiencies and defects during the application of traditional EVM, many questions still cannot be solved just by improving the methods or the models, because of the limitation of itself. For example, costschedule management of EVM does not involve quality management, therefore, it is easy to fall into the wrong region that regards quantity over quality and brings the projects that pay attention to both quality and quantity in danger. Sometimes the project is delayed according to the EVM evaluation because the non-critical projects plans are proposed too early, therefore, when they make the completion measurement baseline; it does not influence the project schedule. Besides, the accidents and human element during the execution of projects can also lead to evaluation results deviating from actual results. Therefore, good control methods do not imply equally good control of the projects. The most important is the capability of the managers to harness the project with information, and make flexible analysis and forecasting combined with the actual situation. Only then the project can be safely and satisfactorily accomplished.

\section{CONFLICT OF INTEREST}

The authors confirm that this article content has no conflict of interest.

\section{ACKNOWLEDGEMENTS}

This work was supported by the Inner Mongolia Natural Science Foundation (2014MS0705) and by Inner Mongolia 
Soft Science Project (20110601) and The National Natural Science Foundation of China (71162015).

\section{REFERENCES}

[1] F. Anbari, "Earned value project management method and extensions," Project Management Journal, vol. 34, pp. 12-23, 2003.

[2] B. Kim and K. Reinschmidt, "Probabilistic forecasting of project duration using kalman filter and the earned value method," Journal of Construction and Engineering Management, vol. 136, pp. 834-843, 2010.

[3] L. M. Naeni, "A fuzzy approach for the earned value management," International Journal of Project Management, vol. 29, pp. 764-77, 2011.

[4] R. Howes, "Improving the performance of earned value analysis as a construction project management: project management tool,"
Engineering, Construction and Management, vol. 117, pp. 399-411, 2000

[5] Fleming \& Keppelman, "Earned value management: mitigating the risks associated with construction projects," Cost Engineering, vol. 9, pp. 32-36, 2002.

[6] H. Cosmo, "Project management-system method of plan, schedule and control," Publishing House of Electronics Industry, vol. 7, pp. 655-670, March, 2004.

[7] H. Fong and W. Little, "An Integrated Cost-Time Approach to Risk Analysis for Construction Projects," CIB W65 Conference Proceeding, Trinidad, 1993, pp. 126-130.

[8] Z. Dan, H. Fang, "Discussion the application of multilayer plan in large projects," Project Management Techniques, vol. 10, pp. 59-65, 2004.

[9] C. David, "The costs and benefits of the earned value management," Process Acquisition Review Quarterly, vol. 5, pp. 373-386, 1998.

Received: January 15, 2015

Revised: March 28, 2015

Accepted: April 03, 2015

(C) Gedi et al.; Licensee Bentham Open.

This is an open access article licensed under the terms of the Creative Commons Attribution Non-Commercial License (http://creativecommons.org/licenses/ by-nc/4.0/) which permits unrestricted, non-commercial use, distribution and reproduction in any medium, provided the work is properly cited. 